\title{
Infant Ross procedure for recurrent aortic stenosis
}

\author{
Martin Runciman, Ingegerd Östman-Smith, Stephen Westaby
}

\begin{abstract}
A male infant underwent an open aortic valvotomy during the second day of life. Aortic stenosis recurred and at the age of eight weeks he underwent a pulmonary autograft aortic root replacement (Ross procedure). The pulmonary autograft procedure is a valuable option in this circumstance.
\end{abstract}

(Heart 1996;76:449-450)

Keywords: Ross procedure; infant; critical congenital aortic stenosis.

\section{Case report}

The patient was born at term after an uneventful pregnancy. A dating and anomaly scan at 23 weeks' gestation was normal. Delivery was by lower segment caesarean section for breech presentation. He weighed $2769 \mathrm{~g}$. A murmur was heard and the femoral pulses were noted to be weak soon after birth.

Examination revealed poor peripheral perfusion with all pulses impalpable. The chest $x$ ray showed a moderately enlarged globular heart. The electrocardiogram demonstrated a sinus tachycardia with marked left ventricular hypertrophy and a left ventricular strain pattern with flat $T$ waves in all limb leads: $T$ waves were inverted in V5 and V6. Cross sectional echocardiography showed situs solitus and normal connections, with an hypertrophied and poorly contracting left ventricle. The aortic valve was thickened and rigid with an orifice diameter of $1 \mathrm{~mm}$. Doppler gradient estimation across the valve was $81 \mathrm{~mm} \mathrm{Hg}$. No other structural abnormalities were demonstrated. He was treated with prostaglandin $\mathrm{E}_{2}$ and digitalis.

At 46 hours an open aortic valvotomy was performed. The valve was bicuspid, dysplastic, and severely stenotic but the valvotomy appeared satisfactory. Immediate postoperative Doppler gradient estimation was $25 \mathrm{~mm}$ $\mathrm{Hg}$, but this had risen to $58 \mathrm{~mm} \mathrm{Hg}$ at the time of discharge 12 days after surgery.

$\mathrm{He}$ was reviewed in clinic at 42 days. Clinically he remained well but the electrocardiogram demonstrated inverted $T$ waves and grossly depressed ST segments in all chest leads. His echocardiogram showed marked left ventricular hypertrophy and reduced function with a maximum Doppler gradient across the aortic valve of $100 \mathrm{~mm} \mathrm{Hg}$. He was started on propranolol with marked improvement of the signs of ischaemia on the ECG. A second valve operation was advised at this stage and at 56 days he underwent a pulmonary autograft (Ross) procedure.

The ascending aorta was transected above the sino-tubular junction and the coronary ostia mobilised from the aortic wall. The severely dysplastic aortic valve was excised completely and the aortic root enlarged by incision into the annulus at the non-coronary cusp. The pulmonary artery was divided just proximal to the bifurcation and the normal pulmonary valve and root were excised. Care was taken to avoid the septal branches of the left anterior descending coronary artery. The pulmonary outflow was reconstructed with a $14 \mathrm{~mm}$ pulmonary homograft and the autologous pulmonary root was used to replace the aortic root. The native coronary arteries were re-implanted into the pulmonary autograft.

His rapid recovery was complicated only by a brief self-limiting episode of 2:1 heart block. At follow up six months later he was in excellent health and growing well along the 25th centile. Echocardiography showed good ventricular function with no areas of dyskinesis. The maximum Doppler velocity from the left ventricular outflow tract to the ascending aorta was $1.3 \mathrm{~m} / \mathrm{s}$, indicating no residual gradient. There was trivial aortic regurgitation and no gradient across the pulmonary homograft.

\section{Discussion}

Ross first described the replacement of the aortic root with a pulmonary autograft 28 years ago. Since then this procedure has been done primarily in adults, although some centres are beginning to report small series in children. ${ }^{1}$ There is little experience with the Ross procedure in infants and neonates. ${ }^{2}$ We believe this is the first published case of a Ross procedure being performed on an infant after the recurrence of the aortic stenosis following an open aortic valvotomy.

There is general agreement that aortic valvotomy is the first line treatment for congenital aortic stenosis, ${ }^{3}$ and that a proportion of infants will not need reoperation. ${ }^{4}$ There is 
debate whether a surgical valvotomy or transcutaneous balloon dilatation offers a better outcome. ${ }^{5}$ It also remains unclear what is the best treatment option in the event of recurrence of the aortic stenosis. There are four choices: (a) another open aortic valvotomy, $(b)$ transcutaneous balloon dilatation, $(c)$ aortic valve replacement with either a mechanical valve or a homograft or, (d) the pulmonary autograft (Ross) procedure.

Though a second open aortic valvotomy may again relieve the stenosis it is unlikely to be a long term cure for dysplastic valves, and further intervention is likely to be required. Transcutaneous balloon dilatation of the valve is feasible but it is only palliative because in many patients the stenosis progresses. ${ }^{6}$

Aortic valve replacement in neonates and infants is only palliative because of somatic growth. Bioprosthetic valves are unsuitable ${ }^{7}$ and mechanical valves are hazardous because of complications of anticoagulation, thromboembolism, prosthetic valve endocarditis, and the need for further reoperation. ${ }^{8}$ Homografts have also been shown to be unsuitable because premature degeneration and calcification lead to early failure and the risk of reoperation is high. ${ }^{9}$ The Ross procedure, despite being a more complicated operation, offers the best outcome because an autologous valve grows with the child, does not undergo primary tissue failure, and obviates the need for anticoagulation. The pulmonary homograft used to reconstitute the right ventricular outflow tract eventually needs replacement but usually not until teenage years.
We conclude that in some infants and children in whom an aortic valvotomy has either not achieved adequate relief of the stenosis or has resulted in severe reflux, an aortic root replacement with pulmonary autograft (Ross) procedure is the best treatment. Infants with a severely dysplastic aortic valve and root may be considered for a pulmonary autograft operation as the primary procedure even in the neonatal period. In some cases the left ventricular outflow tract may need to be enlarged by the Ross-Konno procedure. ${ }^{10}$

1 Schoof PH, Cromme-Dijkhuis AH, Boger AJJC, et al. Aortic root replacement with pulmonary autograft in children. $\mathcal{F}$ Thorac Cardiovasc Surg 1994;107:367-73.

2 Matsuki O, Yagihara T, Yamamoto F, Takahashi $O$ Kamiya T, Kawashima Y. Successful aortic root replacement with pumonary autograft in two infants. Nippon Kyobu Geka Gakkai Zasshi 1994;42:951-5.

3 Vobecky JS, Chartrand C, Angate H, Stanley P. Surgery for critical aortic stenosis in newborns is still good therapy after 25 years. Can 7 Surg 1992;35:489-92.

4 Ettedgui JA, Tallman ET, Neches WH, et al. Long term results of survivors of surgical valvotomy for severe aortic stenosis in early infancy. $\mathcal{F}$ Thorac Cardiovasc Surg 1992; 104:1714-20.

5 Gatzoulis MA, Rigby ML, Shinebourne EA, Redington AN. Contemporary results of balloon valvuloplasty and AN. Contemporary results of balloon valvuloplasty and Surgical valvotomy for

6 Sreeram N, Kitchiner D, Williams D, Jackson M. Balloon dilatation of the aortic valve after previous surgical valvotomy: immediate and follow up results. Br Heart $\mathcal{f}$ 1994;71:448-60

7 Dunn JM. Porcine valve durability in children. Ann Thorac Surg 1981;32:357-68.

8 Milano A, Vouhé PR, Baillot-Vernant F, et al. Late results after left-sided cardiac valve replacement in children. $\mathcal{F}$ Thorac Cardiovasc Surg 1986;92:218-25.

9 Clarke DR, Campbell DN, Hayward AR, Bishop DA Degeneration of aortic valve allografts in young recipiDegeneration of aortic valve allografts in youn
ents. $₹$ Thorac Cardiovasc Surg 1993;105:934-41.

10 Reddy VM, Rajasinghe HA, Teitel DF, Haas GS, Hanley FL. Aortoventriculoplasty with the pulmonary autograft: the "Ross-Konno" procedure. F Thorac Cardiovasc Surg 1996;111:158-65:discussion 165-7. 